\title{
O PSICODIAGNÓSTICO INTERVENTIVO FENOMENOLÓGICO-EXISTENCIAL GRUPAL COMO POSSIBILIDADE DE AÇÃO CLÍNICA DO PSICÓLOGO
}

\author{
Existential-phenomenological Group Interventional psychodiagnosis as a \\ Possibility of the Psychologist's Clinical Action \\ Psicodiagnóstico Intervencionista Fenomenológico-existencial Grupal como \\ Posibilidad de Acción Clínica del Psicólogo
}

Paulo Evangelista

\begin{abstract}
Resumo: Neste artigo apresento o psicodiagnóstico interventivo fenomenológico-existencial como possibilidade de ação clínica do psicólogo. Trata-se de um modelo de intervenção em psicologia em prática nas clínicas-escola da Universidade Paulista (UNIP), onde leciono, tendo sido desenvolvido nessa instituição. Este modelo questiona o lugar hierárquico de saber e poder do psicólogo no método tradicional de psicodiagnóstico, convocando os clientes a assumirem protagonismo na elaboração do conhecimento acerca de si mesmos. Na UNIP este recurso é utilizado no psicodiagnóstico infantil, o que reconfigura o papel da família no processo. A criança não é mais vista como portadora isolada de um 'problema psicológico', já que este é interpretado como um fenômeno do mundo familiar. Ademais, configura-se já como ação psicológica, propiciando o resgate da liberdade para cuidar de si e a autonomia dos clientes. O método compreende entrevistas com pais, sessões de observação da família, atendimentos à criança, visitas à casa e à escola dos participantes. Por fim, elabora-se um relato em linguagem acessível para a criança de seu processo, assim como lêse e discute-se com os pais o Relatório Psicológico, a fim de que se posicionem e assumam a coautoria do mesmo.
\end{abstract}

Palavras-chave: Psicodiagnóstico; Psicodiagnóstico-interventivo; Psicologia fenomenológico-existencial.

Abstract: In this article, I present existential-phenomenological interventional psychodiagnosis as a possibility of psychologist's clinical action. It is a model of psychological intervention developed and in practice at Universidade Paulista (UNIP), where I teach. This model questions psychologists' hierarchic place of power and knowledge in the traditional psychodiagnosis and invites clients to become protagonists in developing knowledge about themselves. This resource is used at UNIP for child psychodiagnosis. By doing so, the family's role is reconfigured in the process. The child is not the sole carrier of a 'psychological problem', since it is interpreted as a phenomenon in the family world. This procedure is already a psychological action since it enables clients to rescue their autonomy and freedom to care for themselves. This method comprehends interviews with the parents, family observation sessions, sessions with the children, visits to the family's house and the children's school. In the end, a report is written in language accessible to the children. Also, the report written by the psychologist is read to and discussed with the parents in order for them to position themselves as its coauthors.

Keywords: Psychodiagnosis; Interventional-psychodiagnosis; Existential-phenomenological psychology.

Resumén: En este artículo presento el psicodiagnóstico intervencionista fenomenológico-existencial como posibilidad de acción clínica del psicólogo. Es un modelo de intervención en psicología en práctica en las clínicas-escuela de la Universidad Paulista (UNIP), donde enseño, desenvueltoen esta misma institución. Este modelo cuestionael lugar jerárquico de saber y poder del psicólogo en el método tradicional de psicodiagnóstico, convocando los clientes a asumieren protagonismo en la elaboración del conocimiento acerca de si mismos. En la UNIP este recurso es utilizado en el psicodiagnóstico infantil. Este reconfigura el papel de la familia en el proceso. El niño no es más visto como portador aislado de un 'problema psicológico', ya que este es interpretado como un fenómeno del mundo familiar. Configura-se ya como acción psicológica, propiciando el rescate de la libertad para cuidar de si y la autonomía de los clientes. El método comprende entrevistas con los padres, sesiones de observación de la familia, atendimientos con los niños, visitas a la casa y la escuela de los participantes. Por fin, elaborase un relato de su proceso en lenguaje accesible para el niño y lése e discutese con los padres el Relatório Psicológico a fin de que se posicionen e asuman la coautoría del mismo. Palavras-clave: Psicodiagnóstico; Psicodiagnóstico-intervencionista; Psicologia fenomenológico-existencial.

\section{Introdução}

O psicodiagnóstico interventivo está fortemente relacionado à minha vida docente, além de ser uma modalidade de prática psicológica com a qual me encantei. Foi no segundo semestre de 2008, quando fui contratado pela UNIP de Sorocaba, que entrei em contato com esta modalidade. Na verdade, fui contratado na segunda-feira à noite para começar na terça-feira à noite. Chegando à clínica, encontrei um grupo de doze alunos que aguardavam 
o novo supervisor, após uma mal cuidada saída da supervisora anterior, que os teria apresentado a este modelo de psicodiagnóstico. Quando da entrevista para contratação, respondi que eu sabia realizar psicodiagnósticos na abordagem fenomenológico-existencial. De fato, eu já tinha realizado processos de psicodiagnóstico fundamentado na fenomenologia existencial. Meu primeiro estágio clínico no curso de Psicologia foi um psicodiagnóstico, como na maioria das universidades. Ademais, sempre que recebo um paciente novo no consultório acabo por realizar, espontânea e intuitivamente, uma avaliação informal (Mito, 1996), isto é, uma exploração da queixa, em direção à demanda, à luz do contexto atual e histórico de vida do novo paciente. Descobri, logo no começo como supervisor de psicodiagnóstico na UNIP, que o que eu havia aprendido era o modelo tradicional de psicodiagnóstico e isso me permitiu vivenciar a diferença entre os dois modelos.

\section{Psicodiagnóstico tradicional}

O psicodiagnóstico que aprendi na faculdade, que hoje chamo (à luz da descoberta do psicodiagnóstico interventivo) de "tradicional”, é um processo psicológico voltado para o esclarecimento da demanda que mobilizou o paciente a buscar ajuda psicológica, com o objetivo de propor o encaminhamento mais adequado. Na faculdade, o psicodiagnóstico que realizei era de um homem de 40 e poucos anos. Estava frustrado com o trabalho e com o casamento. Em cinco sessões realizei com ele um levantamento de como a situação chegou a este momento crítico, que mobilizou a busca por ajuda, e fiz o encaminhamento. Lembro que ao longo das sessões eu me segurava para não fazer perguntas que convidassem reflexões sobre seu modo de se relacionar em casa e no trabalho. Fazia isso, pois entendia que o psicodiagnóstico era um processo de avaliação, que podia (frequentemente deveria) recorrer a testes psicológicos para compreender o sentido do sofrimento apresentado. Assim, embora não tenha aplicado nenhum teste nesse paciente, fiz um levantamento que confirmou aquela que era minha expectativa desde o início dos atendimentos: este homem precisava de psicoterapia. Ademais, minha supervisora era uma ótima psicanalista. Às vezes ela recorria à teoria para iluminar algumas situações da sessão, outras, para explicar por que o paciente agia do modo como agia. Assim, na quinta sessão, retomei com ele o que havíamos explicitado ao longo do processo, expliquei a ele por que (as causas!) de seu sofrimento e realizei o encaminhamento para a mesma clínica da PUC, só que para o setor de psicoterapia. Fiz esse encaminhamento mais ou menos no fim de setembro e não acompanhei posteriormente para saber quando ou mesmo se foi chamado.

Esse modo como procedi está em conformidade com o modelo "tradicional" de psicodiagnóstico. Parte-se do pressuposto de que essa modalidade de prática psicoló- gica visa esclarecer a demanda no momento de chegada ao serviço de psicologia para, em seguida, fazer o encaminhamento correto. Está de acordo com a etimologia da palavra, que vem do "grego diagnõstikós e significa discernimento, faculdade de conhecer, de ver através de." (Ancona-Lopez, 1984, p. 1) Ademais, corresponde a uma das prerrogativas da profissão do psicólogo no Brasil, determinada pela Lei Federal no 4.119 de 1962, regulamentada pelo Decreto ${ }^{0} 53.464$, de 21/01/1964, onde se lê no Art. 4 que "São funções do psicólogo: 1) Utilizar métodos e técnicas psicológicas com o objetivo de: a) diagnóstico psicológico; b) orientação e seleção profissional; c) orientação psicopedagógica; d) solução de problemas de ajustamento" (Brasil, 1962) Assim, ao explicar o sofrimento psicológico do paciente e encaminhá-lo ao serviço adequado, estou realizando um diagnóstico psicológico. Implicado aqui está que eu, psicólogo, tenho um conhecimento científico que, aplicado às situações apresentadas pelo paciente, possibilita uma explicação das causas desse sofrimento. Conhecendo as causas, é possível uma intervenção adequada. Isso também está de acordo com a proposta da psicologia enquanto ciência técnica. Como afirmam Pompéia \& Sapienza (2010), "Neste nosso tempo da técnica, faz muito sentido que, tendo detectado o que a está perturbando, ela [pessoa que sofre] queira saber com objetividade se o terapeuta vai conseguir responder à sua demanda e quanto tempo levará” (p. 129).

No processo que realizei, fiz isso. Identifiquei que havia sofrimento psicológico e que a psicoterapia seria a modalidade de prática psicológica mais adequada para essa demanda. Nem me dei conta então, que estava implicada aqui uma hierarquia na relação com o paciente (provavelmente porque, na condição de quartoanista no curso de Psicologia, eu concordaria com essa hierarquia). Ele me relatou sua vida e eu, detentor do saber psicológico, interpretei-a por ele e para ele, entendendo que a psicoterapia seria o encaminhamento mais adequado.

Passou-se quase uma década para que eu entendesse que o que eu fiz com ele é o que costumeiramente se faz nos serviços de psicodiagnóstico em clínicas-escola; a vasta maioria dos pacientes é indicada para a psicoterapia. Na UNIP, como supervisor de psicoterapia, chegam semestralmente muitos pacientes indicados pelo psicodiagnóstico. Como lá o psicodiagnóstico é a porta de entrada das crianças à clínica-escola, elas são indicadas para a psicoterapia, assim como seus pais. Num levantamento estatístico bem informal dos pacientes atendidos pelos alunos que supervisiono em psicoterapia na UNIP, metade foi indicada pelo psicodiagnóstico.

Todos esses pacientes indicados para psicoterapia também relatam terem passado por uma das consequências do método tradicional de diagnóstico psicológico, por qual o paciente que atendi na PUC também deve ter passado: receberam informações sobre o sofrimento que motivou a busca pelo psicólogo e o encaminhamento e depois tiveram que aguardar meses até serem chamados. Não é à 
toa que muitos pacientes desistem do atendimento nas clínicas-escola antes de o iniciarem; com o longo tempo de demora na fila de espera, ou os sintomas desaparecem, ou buscam atendimento em outros lugares. Esse é, portanto, outro aspecto do psicodiagnóstico tradicional que, quando usado em contextos institucionais, exige reformulações. No consultório particular ele funciona. Aliás, é do modelo de consultório particular que provém. Mas em clínicas-escola e outras instituições voltadas para o atendimento de pessoas que não dispõem de recursos para atendimentos particulares, esse modelo não se adéqua. Frequentemente os pacientes precisam se deslocar de longe, gastando o dinheiro contado para condução, para, após dois ou três meses, terem confirmado pelo psicólogo que realmente precisam de um atendimento psicológico.

Essas mesmas dificuldades acontecem com as famílias que levam seus filhos para as clínicas-escola. As crianças, frequentemente encaminhadas pela escola por problemas de aprendizagem, vêm com seus pais para terem confirmado que precisam passar por um psicólogo. Feito o encaminhamento, precisam esperar até serem chamados, o que geralmente leva meses.

Esse modelo de psicodiagnóstico nasceu nos consultórios particulares, mas não se adéqua à situação de atendimento nessas instituições, aonde as pessoas vêm buscando ajuda para lidar com as dificuldades atuais. Ancona-Lopez (1984) lembra que as pessoas nem se preocupam com o nome do serviço psicológico que estão recebendo; o que lhes importa é conseguir lidar com o sofrimento atual. Mas o psicólogo que realiza o psicodiagnóstico no modelo tradicional acaba por desconsiderar o pedido de ajuda, postergando "a intervenção, empobrecendo um encontro rico de possibilidades" (p. 32).

\section{Psicodiagnóstico interventivo}

Assim, o questionamento deste modelo de psicodiagnóstico surge a partir do encontro com a realidade institucional que encontra. O psicodiagnóstico interventivo aparece como uma modalidade de prática psicológica mais adequada para atender a clientela das clínicas-escola. Por um lado, segue o mesmo objetivo do psicodiagnóstico tradicional, a saber, compreender o que ocorre, o comportamento interpretado como problemático, e para responder ao pedido de modificação por meio de intervenção do psicólogo, indicando o encaminhamento mais adequado, caso necessário. Por outro lado, o psicodiagnóstico interventivo rompe com o conceito de diagnóstico enquanto coleta de dados para que o psicólogo formule uma compreensão sobre o cliente, implicando os clientes no processo de formulação de uma compreensão sobre si mesmos e utilizando os encontros clínicos de maneira a já intervir na dinâmica apresentada, contribuindo para o esclarecimento e para a superação do sofrimento que motivou a busca por ajuda.
Quando em 2008 entrei pela primeira vez para supervisionar um grupo de estagiários de psicodiagnóstico interventivo na UNIP, deparei-me com um modo completamente diverso de prática psicológica, cujo objetivo geral é esse apresentado acima. O grupo era composto por doze estagiários, que formavam duplas. Eles me informaram que em poucos minutos receberíamos seis famílias, previamente chamadas pela clínica-escola, para o psicodiagnóstico.

Ao longo do processo fui descobrindo e compreendendo o sentido deste psicodiagnóstico. Primeiramente, as sessões eram realizadas em grupo. Isso é muito enriquecedor neste processo, pois possibilita aos pais e responsáveis que ouçam as suas histórias, as compreensões que têm dos comportamentos de seus filhos e os modos como já tentaram lidar com os comportamentos tidos como problemáticos. Dessas discussões surgem muitas possibilidades de ação e compreensão da situação atual vivenciada pela família. Lembro-me de uma sessão em que duas mães começaram a narrar as dificuldades de suas próprias infâncias, refletindo sobre como o medo de que seus filhos passassem por situações semelhantes influenciava a rigidez com que os tratavam. Outra se preocupava que seu filho não gostava de brincar na rua. Em grupo, relatou que passou sua infância cuidando da casa, enquanto via seus amigos brincando na rua, que era o que mais desejava. Essas lembranças as sensibilizaram para o quanto a postura excessivamente firme com os filhos poderia estar contribuindo para os sintomas que motivaram a busca de ajuda, o que convidou todas as mães presentes nessa sessão a experimentarem olhar para seus filhos de outro modo. Descobriram que, com a intenção de cuidar, estavam descuidando de seus filhos.

Esta situação revela um dos aspectos do psicodiagnóstico interventivo, que é a implicação dos clientes no seu processo de diagnóstico. Ao considerarem sua participação no sofrimento do filho, estas mães descobrem que os sintomas que motivaram a busca pelo psicólogo não estão isolados na criança. Ao descobrirem-se participantes do sofrimento da criança, descobrem sua condição de possibilidade de superação das dificuldades vivenciadas. Descobrem que o psicólogo não é o único agente de transformação da situação atual, mas os próprios clientes descobrem-se responsáveis pelo que se passa consigo. Descobrem também que no psicodiagnóstico são tão participantes quanto o psicólogo na formulação da compreensão da situação vivenciada (Donatelli, 2013).

Esse modo de proceder exige que o psicólogo mude sua postura. Ele precisa abandonar o lugar de conhecedor para convidar os clientes para que participem, para que caminhem junto e se sintam colaborando. Segundo Ancona-Lopez (1996),

Esta colaboração, no entanto, somente será possível se o psicólogo se abrir para a co-participação do cliente e acreditar que este último pode compartilhar os conhecimentos que se forem configurando durante o processo. É uma atuação que se caracteriza pelo 
fato de o psicólogo partilhar suas impressões sobre (e com) o cliente, levando-o a participar do processo e a abandonar a postura passiva de "sujeito" a ser conhecido. A partir daí, o psicólogo manterá sua escuta voltada para as possibilidades de intervenção. (p. 33)

Yehia (1996) indica que o lugar do psicólogo é o de compreender a pergunta, mas neste contexto em que os interessados são coautores de seu processo, o conhecimento teórico e técnico do psicólogo passa a ser apenas mais um ponto de vista. Trata-se de um ponto de vista embasado em pesquisas e observações que possibilita a organização dos fenômenos clínicos e o desvelamento de um sentido que articule uma compreensão do sofrimento atual, a ser trançado com o saber proveniente dos clientes. No caso do embasamento fenomenológico existencial, o psicólogo contribui com a perspectiva de que o cliente está, a seu modo, respondendo à indeterminação de sua existência e à tarefa de ser, buscando o sentido desse modo. É responsabilidade do psicólogo criar o contexto de aparição de fenômenos clínicos (setting), ou seja, o campo no qual o que aparecer será usado para compreender o sentido da vivência do cliente articulado ao sofrimento que motivou a procura. Também cabe ao psicólogo, em função de sua maior mobilidade e liberdade, coordenar o processo de busca de ajuda psicológica pela família, indicando avaliações concomitantes para esclarecer o pedido se forem necessárias.

Um dos aspectos principais do psicodiagnóstico interventivo é a liberdade para acompanhar o desvelamento do fenômeno que o psicólogo tem diante de si. Por isso, a abordagem psicológica mais pertinente é a fenomenologia existencial. Liberdade não quer dizer falta de delimitações. Quer dizer que se buscam constantemente modos de acesso que facilitem o desvelamento do sentido do sofrimento apresentado. Isso é um dos fundamentos da fenomenologia: "o sentido específico do logos, só poderá ser estabelecido a partir da 'própria coisa' que deve ser descrita, ou seja, só poderá ser determinado cientificamente segundo o modo em que os fenômenos vêm ao encontro" (Heidegger, 1998, p. 65). Por isso, não há técnicas previamente delineadas. $\mathrm{O}$ atendimento aos pais e às crianças (no caso de psicodiagnóstico infantil) é uma 'ferramenta' adequada, pois a situação grupal facilita a manifestação dos modos de se relacionar. Assim, no psicodiagnóstico interventivo se alternam sessões dos pais e dos filhos.

\section{Desvelando os mundos da criança}

Os grupos com as crianças possibilitam a observação e a intervenção nas relações com outras crianças no momento em que acontecem. Assim, frequentemente chegam crianças com a queixa de que são isoladas ou agressivas com outras crianças. Em grupo, pode-se observar como essa criança interage com as demais. Por exemplo, será de fato agressiva ou reage agressivamente quando sente que seu espaço foi invadido? Será que se sente à vontade para brincar com crianças mais velhas ou mais novas, embora não com crianças de sua idade? Em grupo pode-se observar tudo isso. E essa observação, diferentemente do modelo tradicional de psicodiagnóstico, que seria de coleta de dados para formulação de uma compreensão pelo psicólogo para posterior devolutiva e encaminhamento, possibilita que, imediatamente, intervenha-se na situação, investigando e convidando novos modos de ser e estar com outros.

Outras possibilidades de investigação sobre a situação existencial daquele que busca ajuda psicológica são os testes psicológicos (também são prerrogativa do psicólogo) e visitas domiciliar e escolar. Enquanto no modelo tradicional de psicodiagnóstico o interessado vem ao consultório do psicólogo, a visita domiciliar propicia ao investigador vários dados de uma só vez: primeiro, pode conhecer o espaço habitado pelos pacientes, podendo compreender como é este 'mundo' (sua organização, seus aspectos, seus significados). O mundo habitado é organizado e cuidado por aqueles que o habitam, de modo que a casa é reveladora de seus ocupantes e de como significam sua vida (Corrêa, 2004). Ademais, a visita domiciliar torna-se uma ocasião para conhecer outros membros da família, com quem os interessados habitam e compartilham o cotidiano, e os modos como se relacionam. Também possibilita ao psicólogo alguns dados sobre a implicação da família no processo. Aceitam ou rejeitam a visita? Cuidam para receber? Quem recebe? Essas questões compõem a compreensão do envolvimento da família com a situação vivenciada por aquele que apresenta os comportamentos problemáticos, motivando a busca do psicólogo.

A visita escolar também é uma possibilidade nesta modalidade. Frequentemente, as crianças são encaminhadas ao psicodiagnóstico com alguma queixa escolar. Brigam na escola, não conseguem ler ou escrever ou ambos, a professora está preocupada com os comportamentos da criança, etc. Não raro é a escola que aponta que algo não vai bem. Isso é compreensível considerando que o primeiro mundo habitado pela criança é o familiar (Cytrynowicz, 2000a; Cytrynowicz, 2000b). 'Mundo' deve ser entendido como conceito fenomenológico-existencial, isto é, como rede de remissões significativas em que os entes veem à luz sob significados articulados e sustentados pelo para quê da compreensão (HEIDEGGER, 1998). Assim, a família enquanto mundo é uma abertura para a significância dos comportamentos cotidianos, abertura esta que previamente indica os comportamentos certos e errados, legítimos e ilegítimos, possíveis e proibidos. Ao chegar à escola, a criança adentra um novo mundo compartilhado, onde a teia significativa é outra, o que pode revelar novos significados para os velhos comportamentos. Daí que o início da vida escolar coincide com o aparecimento dos comportamentos 'problemáticos' que exigem ajuda psicológica. Alguns comportamentos que em família são tidos como 'normais', no mundo compartilhado escolar não o são. É aquilo que Yehia (1996) chama de "ruptura", uma falta de "algo que deveria haver" ou "quando a criança começa a apresentar atitudes e comportamentos que rompem com 
algumas expectativas dos pais, professores ou de outros agentes da comunidade” (p. 117).

O psicodiagnóstico interventivo considera importante a visita escolar por esta revelar, como a domiciliar, outro mundo habitado pela criança. Ademais, é a oportunidade de conversar com outras pessoas que convivem com a criança - professor, diretor, cuidador, etc. - sobre as compreensões que têm da criança e de seus comportamentos, assim como implicá-los em novos modos de lidar com a criança, sendo esse o caso. Afinal, conhecer alguém é "conhecer a rede de relações da qual esta pessoa faz parte" (Ancona-Lopez, 1996, p. 27), seus contextos. A visita escolar também possibilita uma compreensão dos significados imbricados na organização espacial e física da escola, assim como os valores que sustentam o cotidiano escolar. Há espaço para as crianças brincarem? Como é esse espaço? A escola é limpa, organizada? Como é o barulho? etc. Estes aspectos não têm significados 'em si mesmos', mas podem contribuir para a compreensão global do ser-no-mundo infantil quando confrontados com outros aspectos advindos das situações de observação lúdica, diálogo com os responsáveis, visita domiciliar, etc (Maichin, 2006).

Como psicodiagnóstico, esta modalidade de prática psicológica ainda está focada na compreensão da demanda visando um encaminhamento adequado. Como já visto, entretanto, não se restringe a esse levantamento. O grande diferencial do psicodiagnóstico interventivo é o fato de que, na busca da compreensão da demanda, implicando como participantes dessa busca aqueles que, neste momento, sofrem, esta intervenção favorece o surgimento de novas possibilidades existenciais.

Não se trata de uma nova modalidade que surge de uma especulação teórica. Conforme mencionado há pouco, a população que procura os serviços de clínicas-escola investe seus recursos nesse processo. No modelo tradicional do psicodiagnóstico, a família saía do processo com a confirmação de que precisava de um psicólogo, mas que teria que retornar para iniciar o processo interventivo quando fosse chamada. A proposta de que o psicodiagnóstico seja também uma intervenção surge da compreensão da especificidade do público que busca este serviço, sendo, portanto, fenomenológica. Ao mesmo tempo em que oferece uma ajuda, tal como está sendo buscada, possibilita a compreensão sobre a situação atual e a abertura de novas possibilidades. Isso favorece, inclusive, que o encaminhamento proposto seja seguido. No Centro de Psicologia Aplicada (clínica-escola) da UNIP, os vários pacientes que chegam encaminhados pelo psicodiagnóstico referem-se a esse processo como tendo sido caracterizado por importantes mudanças.

\section{Psicodiagnóstico interventivo como ação clínica}

O fato de propiciar modificações nos modos de ser permite que se considere o psicodiagnóstico interventivo uma modalidade de ação clínica. Alguns autores, como
Yehia (2009) o aproximam do plantão psicológico. Esta modalidade se propõe a acolher a experiência daquele que busca o psicólogo, favorecendo "uma visão mais clara de si mesmo e de sua perspectiva ante a problemática que vive e que gera um pedido de ajuda” (Mahfoud, 1987, p. 76) a partir das possibilidades do próprio cliente no momento em que a procura pelo serviço psicológico acontece. Assim, o plantonista contribui para o resgate da autonomia e da condição de ser-possível daquele que busca ajuda. Faz isso através principalmente do esclarecimento da situação existencial em que está imerso. É o que propõem Cautella \& Morato (2009) com o serviço de plantão psicológico em instituição psiquiátrica: acolher a demanda de forma a contribuir para "articular-se de maneira mais produtiva em relação a essa situação de crise e às suas consequências na dinâmica familiar.” (p. 154) O psicodiagnóstico interventivo pode ser entendido dessa mesma forma, como um modo de responder à necessidade de rearticulação da malha existencial rompida no momento de crise (busca do serviço psicológico). Além disso, Yehia (2009) aponta que, tanto neste psicodiagnóstico quanto no plantão psicológico, o confronto com as compreensões sedimentadas e a conseqüente ruptura dessas pré compreensões possibilita novos modos de agir na situação fáctica. Esse modo de compreender a intervenção em ambas modalidades está sustentado na fenomenologia-existencial, que concebe a ação clínica como "um espaço aberto, condição de possibilidade para a emergência de uma transformação não produzida, mas emergente em forma de reflexão, aqui entendida com quebra do estabelecido e condição necessária para novo olhar poder surgir" (Barreto \& Morato, 2009, p. 50).

\section{Coautoria do saber sobre si}

Essa perspectiva fenomenológica de intervenção, isto é, disponível para acolher a demanda tal como aparece, a partir de sua própria especificidade, exige do psicólogo uma modificação na sua postura tradicional. O psicólogo não tem como fazer isto se estiver apoiado no saber científico sobre o outro, a partir do qual elaborará conhecimentos sobre ele. Esta postura exige participação dos envolvidos, o que coloca o psicólogo na mesma condição do paciente: diante de uma situação desconhecida, aberto para o que se manifestar, tendo que destinar o que aparecer. Ou seja, ambos estão no mesmo barco rumo à modificação da situação atual.

Por fim, é fundamental comentar que ao longo do processo de psicodiagnóstico, são realizadas devolutivas constantes. Elas auxiliam no esclarecimento da demanda e na compreensão da situação, sendo o principal aspecto interventivo deste processo. Levando em conta que os fenômenos aparecem sempre sob um aspecto e que há infindáveis modos de aparecer, no psicodiagnóstico interventivo são demarcadas compreensões que surgem de cada encontro, a fim de que psicólogo e paciente possam 
conjuntamente considerar o que se apresentou. Do ponto de vista fenomenológico a compreensão já é um modo de ação, dado que abre novas possibilidades. Ademais, é fundamental que as compreensões que surgem nos encontros possam ser partilhadas com os participantes. Isso torna necessário que o psicólogo cuide de que sua linguagem esteja em consonância com a dos participantes. Isto é, jargões psicológicos e linguagem técnica não favorecem a compreensão; pelo contrário, distanciam psicólogo e paciente.

Neste modelo de psicodiagnóstico infantil, um dos recursos mais interessantes para o diálogo com as crianças é o livro-história, produzido pelo psicólogo no final do atendimento. O livro-história é uma narrativa da história de vida, da situação atual e do processo de psicodiagnóstico escrito e ilustrado de acordo com a linguagem da criança em atendimento (Becker, Donatelli e Santiago, 2013). A elaboração desses livros nos estágios na UNIP e uma atividade riquíssima tanto pelo modo como favorece a compreensão e a apropriação do processo pelo paciente, quanto pelas descobertas de capacidade criativa e artística dos estagiários.

No psicodiagnóstico interventivo, a devolutiva com o livro-história é seguida de uma devolutiva final com os pais e responsáveis, que tem o mesmo objetivo da devolutiva às crianças. Contribui para quem se apropriem da compreensão e das possibilidades abertas ao longo do processo. No estágio na UNIP isso tem sido feito através de uma leitura conjunta e discussão do relatório psicológico elaborado pelo estagiário. Esta situação também é de troca. O relatório apresentado não é definitivo, pois as considerações, dúvidas, críticas e correções propostas pelos pacientes compõem a redação final, de modo que, fiel à proposta de que todos são coparticipantes deste processo, até o relatório psicológico é elaborado conjuntamente.

\section{Referências}

Ancona-Lopez, M. (1984). Contexto geral do diagnóstico psicológico. Em W. Trinca, Diagnóstico psicológico: a prática clínica. São Paulo: EPU.

Ancona-Lopez, S. (1996). Psicodiagnóstico: processo de intervenção? Em M. Ancona-Lopez (Org.). Psicodiagnóstico: processo de intervenção, 2. ed. São Paulo: Cortez.

Barreto, C. \& Morato, H. (2009). A ação clínica e a perspectiva fenomenológica existencial. Em H. Morato et al. (Org.). Aconselhamento psicológico numa perspectiva fenomenológica existencial: uma introdução. Rio de Janeiro: Guanabara Koogan.

Becker, E.; Donatelli, M. \& Santiago, M. (2013). Metáfora e devolução: o livro de história no processo de psicodiagnóstico interventivo. Em S. Ancona-Lopez (Org.). Psicodiagnóstico interventivo - evolução de uma prática. São Paulo: Editora Cortez.
Brasil (1962). Lei nº 4.119 de 27 de agosto de 1962 (Dispõe sôbre os cursos de formação em psicologia e regulamenta a profissão de psicólogo). Disponível em: < https://www.planalto. gov.br/ccivil_03/leis/1950-1969/14119.htm>.

Cautella, W. \& Morato, H. (2009). Uma prática psicológica inclusiva em hospital psiquiátrico: do cuidado de ser ao resgate de cidadania. Em H. Morato et al (Org.). Aconselhamento psicológico numa perspectiva fenomenológica existencial: uma introdução. Rio de Janeiro: Guanabara Koogan.

Corrêa, L. (2004). Visita domiciliar: recurso para a compreensão do cliente no psicodiagnóstico interventivo. (Tese de doutorado). Pontifícia Universidade Católica de São Paulo, São Paulo.

Cytrynowicz, M. (2000a). O mundo da criança. Revista da Associação Brasileira de Daseinsanalyse, n. 9. São Paulo.

Cytrynowicz, M. (2000b). O tempo da infância. Revista da Associação Brasileira de Daseinsanalyse, n. 9. São Paulo.

Donatelli, M. (2013). Psicodiagnóstico interventivo fenomenológico-existencial. Em S. Ancona-Lopez (Org.). Psicodiagnóstico interventivo - evolução de uma prática. São Paulo: Editora Cortez.

Heidegger, M. (1998). Ser e tempo. Petrópolis: Ed. Vozes.

Maichin, V. (2006). Visita escolar. um recurso do psicodiagnóstico interventivo na abordagem fenomenológico-existencial. (Dissertação de Mestrado). Pontifícia Universidade Católica de São Paulo, São Paulo.

Mito, T. (1996). Psicodiagnóstico formal e avaliação informal. Em M. Ancona-Lopez (Org.). Psicodiagnóstico: processo de intervenção. São Paulo: Cortez.

Pompéia, J. \& Sapienza, B. (2012). Os dois nascimentos do homem: escritos sobre terapia e educação na era da técnica. Rio de Janeiro: Via Verita.

Yehia, G. (1996). Reformulação do papel do psicólogo no psicodiagnóstico fenomenológico-existencial e sua repercussão sobre os pais. Em M. Ancona-Lopez (Org.). Psicodiagnóstico: processo de intervenção. São Paulo: Cortez.

Yehia, G. H. (2009). Entre psicodiagnóstico e aconselhamento psicológico. Em H. Morato et al. (Orgs.). Aconselhamento psicológico numa perspectiva fenomenológica existencial: uma introdução. Rio de Janeiro: Guanabara Koogan.

Paulo Eduardo Rodrigues Alves Evangelista - Doutor em Psicologia Escolar e do Desenvolvimento pela Universidade de São Paulo, Mestre em Filosofia e Graduação em Psicologia pela Pontifíca Universidade Católica de São Paulo. Atua como docente e supervisor clínico na Universidade Paulista (UNIP), sendo também responsável pela elaboração dos planos de ensino e de apostilas para autoavaliação dos alunos (líder de disciplina). Endereço Institucional: R. Dr. Bacelar, 1212. São Paulo - SP - CEP: 04026-002. E-mail: paulo.e.evangelista@gmail.com

Recebido em 14.06.15 Primeira Decisão Editorial em 02.04.16 Aceito em 25.05.16 